\title{
Estratégias enunciativas em Google Spotlight Stories: o olhar da semiótica de Greimas nos vídeos $360^{\circ}$
} Enunciative strategies in Google Spotlight Stories: the look of Greimas' semiotics on the $360^{\circ}$ videos

Ana Silvia Lopes Davi Médola ${ }^{1}$

Bruno Jareta de Oliveira ${ }^{2}$

\footnotetext{
${ }^{1}$ Ana Silvia Lopes Davi Médola é livre-docente em Comunicação Televisual pela Unesp; é docente do Departamento de Comunicação Social - Curso de Radialismo - e do Programa de Pós-Graduação em Comunicação. É líder do Grupo de Estudos Audiovisuais (GEA - Unesp). E-mail: asilvia@faac.com.br

${ }^{2}$ Bruno Jareta de Oliveira é doutorando em Comunicação pela Universidade Estadual Paulista e membro do Grupo de Estudos Audiovisuais (GEA - Unesp). E-mail: brunojareta@hotmail.com
} 
Resumo: as lógicas de linearidade e práticas de fruição e interação introduzidas pelos vídeos $360^{\circ}$ para dispositivos móveis e aparelhos de realidade virtual constituem um marco na forma expressiva audiovisual. Ao subverter a dinâmica da montagem como elemento fundante dos efeitos de continuidade, os vídeos $360^{\circ}$ introduzem nova racionalidade na representação do espaço e conferem ao espectador parte do poder de decisão sobre o que ver. Sistema de significação próprio das tecnologias digitais, a visualidade inaugurada nos vídeos $360^{\circ}$ recebe neste trabalho o olhar da semiótica greimasiana sobre as estratégias enunciativas que regem novas formas de espacialização e efeitos de imersão no audiovisual.

Palavras-chave: vídeo $360^{\circ}$; realidade virtual; linguagem audiovisual; enunciação; Google Spotlight Stories.

\begin{abstract}
: the logics of linearity and fruition and interaction practices introduced by $360^{\circ}$ videos for mobile and virtual reality devices constitute a milestone in the expressive audiovisual form. By subverting the dynamics of editing as a founding element of continuity effects, $360^{\circ}$ videos introduce new rationality in the representation of space and give the viewer part of the power of decision on what to see. As a system of meaning specific to digital technologies, the visuality inaugurated in $360^{\circ}$ videos is addressed in this article by the greimasian view of semiotics on the enunciative strategies that rule new forms of spatialization and effects of immersion in audiovisual form.
\end{abstract}

Keywords: $360^{\circ}$ video; virtual reality; audiovisual language; enunciation; Google Spotlight Stories. 
A maneira como o público se relaciona com o audiovisual tem apresentado significativas mudanças graças às possibilidades técnicas e estéticas abertas pelos meios digitais, que reconfiguram as práticas interacionais e introduzem novas experiências de fruição. O vídeo $360^{\circ}$ para dispositivos móveis está entre as produções contemporâneas que não somente ampliam as relações de comunicação, mas subvertem lógicas de articulação de linguagens audiovisuais consolidadas ao longo do século XX, instaurando formas expressivas fundadas na imersão tanto projetiva quanto somática, a qual requer uma ação corpórea. Isso porque o vídeo em $360^{\circ}$, também denominado panorâmico, esférico, omnidirecional e surrounded, compreende a ação do receptor em um processo de agência, conforme descrito em Murray (2003), para que as narrativas se concretizem.

A forma de registro do vídeo $360^{\circ}$ consiste em captar (ou gerar, no caso de animações) imagens a partir de um ponto de captação que registre todos os ângulos, ou seja, todas as imagens ao redor desse ponto. O resultado pode ser exibido em dispositivos baseados em uma tela bidimensional, como os smartphones e aparelhos de realidade virtual, ou em superfícies esféricas de projeção que ofereçam a possibilidade de orientação visual mediante interação para quem assiste ao conteúdo, de modo que a imagem possa ser visualizada em uma dinâmica de "navegação" durante a exibição.

Considerando que o vídeo panorâmico para diferentes dispositivos é resultante da convergência dos meios em um contexto tecnológico e cultural pautado por significativas alterações nas práticas de produção e consumo audiovisual, a reflexão a partir da perspectiva dos estudos de linguagem e das condições da apreensão e de produção do sentido (GREIMAS; COURTÉS, 2008, p. 415) orientam a reflexão em um fazer comunicacional que desafia as noções consolidadas de "tela”, “imersão" e "instância da enunciação", identificadas como questões fundamentais para pensar as características próprias do vídeo $360^{\circ}$. A compreensão acerca das dinâmicas que regem o fazer enunciativo nos vídeos panorâmicos abre perspectivas para a inovação nos processos produtivos e contribui para dimensionar em que medida essa forma de textualização audiovisual pode estabelecer novos contratos enunciativos nas relações de comunicação.

Quatro produções ficcionais foram selecionadas para compor o corpus de análise: Windy day, Buggy night, Duet e Help. Todas são frutos de um mesmo projeto do Google, chamado Spotlight Stories, e foram selecionadas em função dos seguintes critérios: exploram as especificidades discursivas dos vídeos $360^{\circ}$; apresentam uma narratividade com enunciados articulados nos quais se pode identificar elementos do esquema canônico do nível narrativo do percurso gerativo de sentido; e, somadas, apontam diferentes lógicas de linearidade e práticas de fruição³.

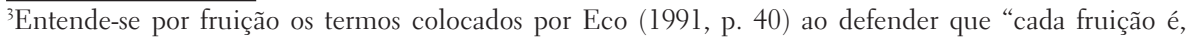


As Spotlight Stories são pequenas histórias interativas contadas em vídeos panorâmicos e disponíveis no aplicativo Google Spotlight Stories ${ }^{4}$. O projeto foi originalmente concebido na unidade de Projetos e Tecnologia Avançada da Motorola (Advanced Technology and Projects, ou ATAP) durante o rápido período em que a companhia era uma subsidiária do Google, mas a unidade não acompanhou a empresa quando ela foi comprada pela Lenovo, migrando para a divisão de Android (sistema operacional para dispositivos móveis), Chrome (navegador web) e aplicativos do Google. O título do projeto faz alusão a um "feixe de luz" em que, como numa peça teatral, nada que está fora da área iluminada pode ser visto. Nas histórias do aplicativo, o público é o manipulador desse feixe.

A primeira narrativa é Windy day, que foi lançada em outubro de 2013 e conta a história de um rato em busca de um chapéu num dia com muito vento em meio a uma floresta; a segunda, Buggy night, lançada em março de 2014, se passa na mesma floresta da primeira, mas durante a noite, e mostra um grupo de insetos tentando não ser devorado por um enorme sapo; a terceira, Duet, de novembro de 2014, conta a trajetória de um garoto e uma garota desde que eram bebês; e a quarta história, chamada Help, disponibilizada em maio de 2015, acompanha uma mulher fugindo de uma criatura alienígena que cai em uma cidade do planeta Terra5.

A semiótica discursiva de linha francesa, enquanto constructo teórico que rege a presente análise sobre o vídeo panorâmico, objeto audiovisual cuja especificidade introduz elementos diferenciais em relação ao cinema e à televisão, demostra a potência da aplicação e constante desenvolvimento do campo conceitual inaugurado por Greimas em seu postulado que concebe a semiótica enquanto um projeto teórico constantemente tensionado pela relação entre o olhar semiótico e o objeto analisado. Tensão esta que resulta em importantes avanços analíticos, ao mesmo tempo em que reafirmam a consistência da base conceitual da semiótica discursiva.

\section{Vídeos $360^{\circ}$ e a linearidade audiovisual}

Para compreender de que maneira o vídeo panorâmico introduz novas práticas no modo de fruição audiovisual, isto é, o estatuto do olhar e o modo de

\footnotetext{
assim, uma interpretação e uma execução, pois em cada fruição a obra revive dentro de uma perspectiva original". Cada duração na qual o destinatário está em contato com o enunciado objeto desta pesquisa, navegando pelas escolhas possíveis e interpretando os desdobramentos oferecidos por ele será nomeada, aqui, de fruição.

${ }^{4}$ nstruções para download do aplicativo disponíveis em: <https://goo.gl/9vt6rK>. Acesso em: 19 out. 2017.

${ }_{5}$ Para facilitar a compreensão das obras, o leitor tem a possibilidade de fruir cada uma das narrativas analisadas neste trabalho, disponíveis em: <https:/goo.gl/QMJiYR> Acesso em: 19 out. 2017.
} 
construção de uma visualidade, torna-se necessário refletir sobre a relação entre as estratégias enunciativas que forjam a matriz do audiovisual. Um primeiro aspecto que deve ser observado é o da representação plástica do espaço tridimensional na tela bidimensional. A invenção do cinematógrafo e, posteriormente, de outras formas de captação, permitiu que a imagem fosse representada seguindo os fundamentos da perspectiva renascentista. Como aponta Machado:

\begin{abstract}
Esse sistema, nascido e florescido no Renascimento, procurava obter uma sugestão ilusionista de profundidade com base nas leis "objetivas" do espaço formuladas pela geometria euclideana. No caso, o suporte matemático parecia dar garantias de racionalidade às suas projeções gráficas. Dizia-se, naquela época, que por ser um sistema de representação fundado nas leis científicas (leia-se euclideanas) de construção do espaço, a perspectiva renascentista deveria nos dar a imagem mais justa e fiel da realidade visível. (MACHADO, 1984, p. 53).
\end{abstract}

$\mathrm{Na}$ busca por essa representação fiel do mundo empírico, a perspectiva renascentista traz como resultado imagens que apresentam uma hierarquia de proporções que simulam a distância relativa dos objetos em um espaço tridimensional, sempre submetida a um centro visual, um olho abstrato, e consequentemente é definida assim a posição que o sujeito do olhar ocupa nesse quadro (MACHADO, 1984). Desta forma, nos dispositivos ópticos de captura de imagem baseados na perspectiva renascentista, o olhar do espectador é o mesmo da câmera, e esse artifício é parcialmente responsável por colocá-lo “dentro" da cena (MACHADO, 1997). Há, no entanto, uma consequência: esse olhar é fixo e único. Para o registro de imagens em movimento, apenas a captação fixa pode não ser suficiente para garantir inteligibilidade. Nas primeiras obras cinematográficas, não era raro o público não ter o olhar atraído para a ação pretendida pelo cineasta, pois outros elementos visuais na cena chamavam a atenção. Soma-se à imagem perspectivista, portanto, outro recurso fundamental de linguagem que norteia a produção cinematográfica desde sua origem, a montagem. Combinadas, ambas viabilizam a produção de efeitos de sentido na construção da narratividade, sobretudo como recurso de direcionamento do olhar.

Sergei Eisenstein (2008) defende em A forma do filme que a montagem não deve ser compreendida apenas como uma ligação de peças que formam uma cadeia, mas, além disso, como um conflito gerado a partir de colisões entre duas peças. Andrei Tarkovski (1998), outro importante cineasta russo, ressalta no livro Esculpir o tempo que a montagem não pode ser superestimada e alega que não é ela a principal responsável pelo ritmo do filme. O cineasta atribui essa responsabilidade ao fluxo de tempo impresso no fotograma, dizendo que a montagem é responsável apenas 
pela estruturação da obra cinematográfica. Ainda segundo o cineasta, "a montagem é prevista durante a filmagem, é pressuposta no caráter daquilo que se filma, está programada desde o início" (TARKOVSKI, 1998, p. 141).

Buscar maneiras de garantir a compreensão do filme passa a ser uma preocupação para aqueles que faziam cinema nos anos que sucederam a sua invenção, quando alguns passaram a capturar imagens mais próximas da ação e, embora não soubessem exatamente como colocá-las no filme, faziam experimentações (MACHADO, 1997). O cinema evoluiu na medida em que os recursos e possibilidades técnicas de seu suporte - a câmera, a película e a projeção em um anteparo - foram explorados, juntamente com experimentações nos modos de utilização, fruição e recepção do conteúdo produzido.

O corte, recurso enunciativo fundamental para a configuração do ponto de vista, isto é, do direcionamento do olhar do espectador, ao ser incorporado à linguagem audiovisual, institui o princípio de continuidade, que, por sua vez, é responsável por uma forma de legibilidade que emana da justaposição dos quadros, capaz de produzir, no plano do conteúdo, efeitos de sentido tanto de linearidade quanto de não-linearidade em uma narrativa. À medida que experimentações eram realizadas nesta direção, tornava-se evidente a relevância estrutural do corte na articulação dos elementos significantes a partir dos eixos da seleção e da combinação, que organizam, na manifestação sincrética do audiovisual, outros recursos enunciativos relativos à imagem, como posicionamentos e movimentos de câmeras na organização de uma visualidade voltada à ação revelada em programas narrativos. Os procedimentos enunciativos que direcionam o olhar do observador por meio da montagem representaram, nos primórdios do desenvolvimento do audiovisual, uma forma de conectar e dar sentido à união dos quadros, possibilitando o fazer interpretativo, ou seja, caminhos de leitura.

Ao considerar as linguagens como sistemas de significação e de produção de sentido nos quais as grandezas semióticas são articuladas em sistema e processo, correlatos às noções de língua e fala do fundador da linguística moderna, o suíço Ferdinand de Saussure, Hjelmslev (1975) define o sistema como um conjunto de elementos que podem substituir uns aos outros, e o processo como as combinações desses elementos. O sistema corresponde ao eixo paradigmático de uma linguagem, baseado na relação de seleção dos elementos virtualizados em determinado código, e o processo, ao sintagmático, regido pela relação de combinação entre tais elementos. Segundo o autor, esses conceitos são aplicáveis a todos os níveis de organização da linguagem.

Da organização sintagmática decorre a linearidade, apontada por Fiorin (2005, p. 65) como a característica que diz respeito a como os signos são dispostos 
através do tempo e do espaço. Conforme resume Bertrand (2003, p. 114), a linearidade obriga a apresentar de maneira sucessiva o que é simultâneo. As línguas naturais, por exemplo, são lineares (possuem uma única dimensão temporal), e por isso não se pode falar ou escrever mais de uma palavra ao mesmo tempo, já outras linguagens possuem significantes não lineares e se apresentam simultaneamente a quem as apreendem - como as visuais, por exemplo (FIORIN, 2005, p. 65).

$\mathrm{Na}$ construção audiovisual, ao selecionar possibilidades num eixo paradigmático e ordená-las numa cadeia sintagmática, temos significados construídos a partir de uma forma de linearizar imagens captadas. A linearidade do audiovisual é resultado, portanto, das suas propriedades: imagens enquadradas dispostas sequencialmente em uma tela em um fluxo temporal. Desse modo, há que se considerar uma dimensão temporal, já que, a rigor, existe um quadro após o outro, mas também há uma dimensão espacial que corresponde ao que está representado nos quadros. Entretanto, tais coerções de textualização próprias da enunciação audiovisual não são necessariamente homologáveis aos efeitos de linearidade e/ou sequencialidade no plano do conteúdo, seja no nível semionarrativo ou discursivo.

A montagem manifesta não apenas a ordem construída pelas estratégias enunciativas relativas à imagem, mas também ao áudio. Com a introdução do som no cinema, Chion (2011, p. 41) constata que enquanto no plano visual há uma relação entre a superfície espacial e a dimensão temporal, no sonoro a dimensão temporal predomina, e a espacial parece não existir: o som "mergulha no fluxo temporal". O autor afirma que a construção da cena tem como referência a imagem, pois "o som é o contido ou o incontido de uma imagem", de modo que a busca por uma espacialização do som ganhou novas possibilidades com o áudio multipista (CHION, 2011). Se a imagem sugere que há alguém vindo pelo lado direito da tela, por exemplo, e sons de passos são emitidos só do lado direito, é simulada uma experiência sonora mais próxima da realidade.

Assim, a aspectualização espaço-temporal da montagem clássica, capaz de instaurar o ponto de vista do observador, é um dos procedimentos enunciativos no qual é possível identificar alterações nos modos de discursivização do vídeo $360^{\circ}$, conforme veremos adiante. Pois, diferentemente desta tecnologia, a base estabelecida pelo meio cinematográfico, isto é, a montagem de sequências visuais reunidas por um fluxo ininterrupto de movimento no espaço, não se alterou ou deixou de existir com os avanços técnicos. Ao contrário, os incorporou em novas possibilidades artísticas ao registro audiovisual, mas sempre sob a lógica da montagem clássica pelas coordenadas do paradigma e do sintagma. Cores e simulação de três dimensões são exemplos desses avanços. 
Porém, no tocante ao vídeo $360^{\circ}$, a montagem perde o estatuto de procedimento enunciativo estruturante da articulação entre os eixos de seleção e combinação de imagens e de sons capazes de produzir coerência narrativa por meio da sequencialidade temporal de planos. Neste modo de representação, tal sequencialidade só é operada por uma ancoragem no plano do conteúdo, uma vez que a captação da imagem produz a simultaneidade dos ângulos. Isto estabelece novos parâmetros na relação de comunicação por alterar a práxis de fruição audiovisual, engendrados pela instância da enunciação a partir das possibilidades de textualização que a tecnologia confere à tela em articulação às estratégias discursivas voltadas a produzir a imersão do enunciatário.

\section{Tela, imersão e instância da enunciação}

A premissa de que a semiótica se ocupa do estudo da forma, seja do conteúdo ou da expressão (FLOCH, 1985, p. 191), conduz a presente reflexão sobre a configuração dos vídeos $360^{\circ}$ no âmbito do audiovisual. Sendo a instância da enunciação o lugar de colocação em discurso, de mediação que permite a passagem das estruturas semióticas virtuais às estruturas realizadas sob a forma de discurso (GREIMAS; COURTÉS; 2008, p. 146), identificou-se no vídeo $360^{\circ}$ especificidades relativas à função da tela, enquanto elemento de textualização capaz de circunscrever o espaço visível, assim como em relação ao estatuto da ancoragem figurativa, enquanto procedimento discursivo condutor da imersão espacial do enunciatário no processo de fruição.

Nessa grade de leitura procurou-se observar as estratégias discursivas nos vídeos $360^{\circ}$ aqui analisados, que introduzem novos contratos enunciativos e práticas de consumo. Em The language of new media, Manovich (2001) lembra que a tela é um espaço virtual tridimensional enclausurado em uma superfície plana retangular, que, posicionada em nosso espaço real, é uma herança da tradição pictórica. Para o autor, a tela tem a agressiva função de recortar, de tirar do ambiente virtual o que quer ser mostrado e apresentá-lo em outro ambiente. Por esse motivo e para evitar a dispersão, o espectador no cinema é convidado a integrar-se completamente ao universo narrativo proposto - por isso, a enorme tela, as luzes apagadas e a imposição do silêncio (MANOVICH, 2001).

O fato é que as histórias emanadas das telas propõem contratos de leitura que, por meio de fazeres interpretativos, levam ou não à adesão dos enunciatários, forjando em última instância formas de imersão. O observador adentra à narrativa por mecanismos de identificação, pela modalização de um querer saber, por uma 
experiência sensível ou por outras condicionantes associadas, que somente a análise poderá indicar. O relevante, segundo Murray (2003), é que uma narrativa em qualquer meio "pode ser experimentada como uma realidade virtual [...] que pode obliterar o mundo à nossa volta” (MURRAY, 2003, p. 101).

Para a autora, esta possibilidade de adesão à narrativa opera na esteira da “imersão”, metáfora da experiência física de estar submerso na água, presente em qualquer modo de representação, obtendo nas narrativas a mesma sensação, do ponto de vista do imaginário, de estarmos completamente cercados por outra realidade. No tocante aos vídeos $360^{\circ}$ aqui analisados, a imersão em um universo narrativo também pode ser articulada por uma ancoragem figurativa no nível discursivo, atuando inclusive como um conector que concretiza a agência e a navegação do enunciatário na narrativa. Se, de acordo com Murray (2003), "imersão", juntamente com "agência" e "transformação", compõem três características no processo de fruição em um ambiente digital, na perspectiva semiótica é a instância da enunciação que concretiza o discurso por meio das projeções de tempo, espaço e pessoa no âmbito da sintaxe, e dos temas e figuras na semântica do nível discursivo do percurso gerativo de sentido (FIORIN, 1996). O enunciado é, portanto, algo construído a partir de um olhar, não sendo possível que exista sem que esteja submetido a uma orientação de um ponto de vista (BERTRAND, 2003). Nesse sentido, qualquer "montagem" manifestada na tela transporta o enunciatário para um universo narrativo criado pela enunciação. Nos vídeos $360^{\circ}$, o contrato proposto confere ao enunciatário o poder de escolher a orientação do olhar, como evidenciam as análises das Spotlight Stories.

\section{Windy day, Buggy night, Duet e Help}

A análise dos objetos aponta para uma narratividade pouco complexa, ainda bastante experimental, mas programada para evidenciar um tipo de interação atualizada somente a partir de escolhas do enunciatário, numa demonstração do potencial da tecnologia. Em Windy day, em que um rato persegue um chapéu, a articulação da narrativa é construída de tal forma que, caso algo específico não esteja sendo olhado, ela não continua. Por meio desse artifício, é possível garantir que os pontos essenciais da narrativa sejam vistos. No começo da história, por exemplo, após o chapéu levado constantemente pelo vento parar por alguns segundos em frente à toca do rato, se o enunciatário decidir redirecionar o olhar para outro ponto, o andamento da narrativa é pausado. Não há nada além da floresta nas outras direções, mas a música que acompanha os movimentos do chapéu cessa quando ele também 
para, e só o som ambiente continua até que toca e chapéu sejam escolhidos. Essa estratégia baseada em uma articulação do visual com o sonoro a partir da lógica da computação programática permanece em outros pontos da narrativa. Em um outro exemplo, quando o rato entra na árvore, ele passa por dois esquilos. Se o enunciatário não acompanhar o rato saindo do tronco e permanecer nos esquilos, verá os dois começarem a brigar, estabelecendo um programa narrativo de uso que se repete até que o olhar volte ao rato em busca do chapéu.

Tal estratégia torna possível não só a garantia do acompanhamento do percurso narrativo do rato e da apresentação de programas de uso mais simples (como esse dos esquilos), mas é fundamental na enunciação, pois é a partir dela que são instauradas as categorias de espaço e pessoa. $\mathrm{O}$ enunciador tem todas as outras orientações que não estão sendo vistas para promover alterações visuais sem que elas sejam percebidas. Com essa estratégia, não só o espaço da história muda a todo o momento, como novos sujeitos são introduzidos. O tempo, a outra categoria enunciativa, é construído assim que a história começa, e a duração da narrativa é a experiência da fruição, que, dependendo da navegação, pode ser mais curta ou mais longa.

Outro fator importante identificado nas análises é a consequência das escolhas de "recorte" feitas com a manipulação do dispositivo. Não é possível ver tudo o que está acontecendo na história: a escolha da orientação é imperativa e inevitável. As estratégias discursivas de atração do olhar induzem o enunciatário a acompanhar determinados elementos em detrimento de outros. Aderindo ou não às estratégias de manipulação do enunciador em conduzir a sua atenção, o observador forçosamente recorta a imagem disponível para enquadrá-la nas dimensões da superfície da tela do dispositivo à medida que seleciona o que ver. Esta experiência se assemelha à que temos no mundo natural, já que não podemos enxergar simultaneamente tudo a nossa volta sem mover o corpo. Nestas escolhas para decidir o que ficará dentro do quadro ou fora dele, observa-se a variação englobado/englobante: há um ambiente audiovisual ao redor (englobante) do qual uma parte (englobado) será recortada para caber nos limites da tela do celular. É relevante destacar que a narrativa se utiliza desta mesma lógica para construir sentidos.

Em Buggy night, evidencia-se também a sincretização da instância enunciativa e narrativa. Nesta história, o observador é enunciatário que assume papel actancial no desenvolvimento dos programas narrativos. Ele atua simultaneamente como oponente do grupo de insetos e adjuvante do sapo, pois é através da luz controlada por ele que o grupo fica exposto ao ataque do predador. Assim como Windy day, a programação não permite que a narrativa evolua se os insetos não 
forem mirados pela orientação do aparelho, e contribuir com o sapo é inevitável para o avanço da história. Observa-se que a utilização do vídeo panorâmico como recurso para posicionar espacialmente o enunciatário é explorada narrativamente em Buggy night, e apesar do espaço ao redor se modificar de forma semelhante ao de Windy day, o ponto de captação é fixo no decorrer da narrativa.

Ao contrário de Windy day, onde a figura do chapéu ancora a produção da linearidade narrativa na navegação do enunciatário, em Buggy night, a ancoragem nas figuras dos insetos induz a uma não linearidade. Enquanto a primeira história busca conduzir a atenção do público a todo momento, na segunda ela é constantemente desorientada. Quando o grupo de insetos se separa, cada um deles vai para uma direção, impossibilitando um percurso de leitura único para continuar acompanhando a história. Mesmo tentando seguir o movimento em detrimento do que está parado, é impossível linearizar a atenção quando caminhos simultâneos são apresentados, e a alta velocidade dos insetos contribui para que o enunciatário não tenha tempo nem de julgar qual inseto escolher para acompanhar. E, ainda que tivesse, os animais desaparecem para reaparecerem no ponto seguinte, impossibilitando uma continuidade. De qualquer forma, o efeito de sentido de desorientação causado pela rápida separação do grupo permanece. Se o enunciatário demorar a encontrar o novo ponto de encontro dos insetos, um mecanismo de retomada de atenção é usado: pegadas aparecem no chão, representadas por pequenos pontos.

É interessante notar que Buggy night utiliza a perspectiva sonora - definida por Machado (2007, p. 112) como um recurso que combina alterações de intensidade e "aspecto" dos sons (como a reverberação) para sugerir o posicionamento de um ponto de escuta na cena - também como uma estratégia de condução da atenção. Quando o aparelho é orientado para cima e vemos o céu estrelado da floresta, a música não diegética que acompanha a narrativa tem a intensidade reduzida, e uma nova melodia passa a acompanhar a imagem da lua e das estrelas. Quando o chão volta a ser olhado, a primeira melodia é retomada. O som é então associado à navegação do audiovisual panorâmico.

Duet difere-se das narrativas anteriores por apresentar três sujeitos, oferecendo ao enunciatário a possibilidade de acompanhar diferentes trajetórias: a do garoto, a da garota e a do cachorro. Os sujeitos ora estão reunidos ora separados, o que obriga o enunciatário a escolher qual deles será acompanhado a partir da orientação visual do dispositivo. Há, no entanto, tempo hábil para que tal decisão seja feita, pois as separações acontecem em uma velocidade possível de acompanhar (diferente dos momentos em que o grupo de insetos de Buggy night se separam, causando desorientação). 
Na experiência de navegação em Duet destaca-se a figuralidade na projeção figurativa da cena, na qual os formantes eidéticos produzem traços que se transformam a partir de si e se moldam continuamente, estabelecendo um paralelo com a lógica do fluxo contínuo das cenas sem cortes. Os espaços cênicos são construídos com a essencialidade das figuras, possuindo menos densidade sêmica que a floresta das histórias analisadas anteriormente. É representado pelo desenho apenas o mínimo para que possamos identificar o que está sendo retratado, decorrendo daí a principal estratégia para instaurar espaço e tempo: traços que se modificam durante a narrativa. Duet, sem cortes, apresenta as histórias simultâneas de duas vidas, desde o nascimento até o "fim", contadas em uma duração de quase três minutos. É possível acompanhar o tempo todo o mesmo bebê até a forma adulta, e o desenvolvimento é sutil, porque os traços se modificam à medida que a história vai acontecendo - e é esse desenvolvimento gradual dos traços que estabelece a noção de tempo da narrativa, permitindo a compreensão de que Duet apresenta uma versão "acelerada" destas trajetórias (já que no mundo natural nenhum bebê fica adulto em minutos). Da mesma forma, o espaço é retratado por traços que surgem e desaparecem quando os personagens interagem com eles. Conclui-se, portanto, que a instauração do espaço sem o recurso do "corte" também é resolvida com esta estratégia, com as alterações acontecendo aos olhos do público (diferente de Windy day e Buggy night, que ocultam essas modificações).

A oposição englobado/englobante também está presente em Duet para construir diferentes significados, como no momento em que o cachorro separa o casal. O cão é atraído por algo que não é possível enquadrar junto com os outros dois sujeitos. Caso o enunciatário não tenha visto o que atraiu o cachorro e reveja a história optando por acompanhá-lo, descobrirá que um esquilo chama a sua atenção e, por esse motivo, ele arrasta o dono que o prendeu pela coleira. O casal se separando e o cachorro tentando pegar o esquilo são ações simultâneas, porém impossíveis de serem visualizadas no mesmo enquadramento. Essa estratégia revela o propósito de se criar uma narrativa que possa ser vista mais de uma vez, oferecendo diferentes significados em função do percurso narrativo realizado.

Em Help, quarta produção selecionada para compor o corpus, o enunciatário não possui um papel actancial como em Buggy night: ele é testemunha da história, podendo olhar para todos os lados enquanto a catástrofe acontece na narrativa. Estratégias observadas nas histórias anteriores para conduzir o olhar do enunciatário também são utilizadas nesta Spotlight Story. Destacamos, no entanto, como ponto mais evidente em que esta história difere das demais, o fato de ser interpretada por atores reais, e não em animação. Talvez esse motivo tenha dificultado a criação de 
pontos obrigatórios a serem vistos. Esse fator amplia o risco de que algo crucial para a compreensão do enredo, como o raio disparado acidentalmente pela mulher no início da história, seja perdido, ocasionando uma não compreensão ao final da fruição.

No âmbito da composição imagética, verifica-se que a gestualidade constitui a base de uma nova estratégia para promover percursos visuais de leituras. $\mathrm{O}$ corpo humano, enquanto "volume em movimento", exprime na gestualidade sinais e expressões que produzem sentido (GREIMAS; COURTÉS, 2008, p. 210). Momentos distintos na narrativa apresentam gestos e reações dos sujeitos que induzem a um caminho visual de leitura. Quando o policial e a mulher estão dentro do trem, por exemplo, ele aponta para a criatura que os persegue. Esse gesto orienta o enunciatário a posicionar o dispositivo na direção do alienígena, que em seguida começa a destruir o vagão.

Enquanto as narrativas anteriores não possuem diálogos entre os personagens, Help utiliza algumas falas no decorrer dos seus aproximados cinco minutos de duração como recurso para orientar a visão do enunciatário. Essa estratégia exige uma compreensão do conteúdo dos textos verbais ditos oralmente pelos sujeitos do enunciado. Na estação do metrô, por exemplo, o policial grita: "Go! In the train!”. Há, a partir da voz, um referencial figurativo, o trem, que funciona como próximo ponto de orientação da visão caso o enunciatário esteja direcionando o dispositivo móvel para outra direção. Assim, qualquer que seja o arranjo enunciativo que articula linguagens nos vídeos $360^{\circ}$ aqui analisados, o principal objetivo no processo de fruição é o de não apenas instaurar o enunciatário em imersão enquanto projeção no discurso, mas torná-lo um actante da enunciação, agenciador dos avanços narrativos.

\section{Spotlight Stories: enunciação para uma fruição orientada}

Ao privilegiar os arranjos enunciativos das quatro narrativas do projeto Spotlight Stories a partir da relação entre tela, montagem e imersão, identificouse que a primeira diferença clara entre o audiovisual clássico e o panorâmico é a nova linearidade estabelecida. A sequencialidade na montagem, pautada sobretudo na temporalidade, ganha uma nova importância na espacialidade. O dispositivo topológico audiovisual panorâmico amplia as possibilidades de textualização não apenas por se atualizar em ato (imagens em movimento), mas também por permitir a navegação no ambiente representado: os elementos visuais que estarão na tela (espaço) no decorrer do fluxo de projeção (tempo) dependerão também da orientação definida pelo enunciatário para serem visualizadas. 
Outro aspecto relevante são as interações discursivas entre os sujeitos da enunciação. Segundo Oliveira (2013, p. 235), “o processo comunicacional instaura percursos de articulação lógica dos elementos integrantes do arranjo que tracejam a trajetória de processamento da significação", e tal configuração se viabiliza pelo conjunto de ações entre os sujeitos do discurso. Esse poder que é cedido ao enunciatário faz com que o enunciador não tenha certeza do que aparecerá na tela em cada um dos momentos de fruição do vídeo. No entanto, todas as possibilidades do enunciado estão regidas por uma programação e por estratégias discursivas produzidas pelo enunciador. Uma nova lógica de linearidade é estabelecida, mas isso não dá total controle ao destinatário-enunciatário: ele continua vendo e ouvindo apenas o que o destinador-enunciador construir como enunciado. Desta forma, a situação enunciativa estabelecida é de transitividade entre os atores, e a colocação discursiva respeita uma "orientação fixada a partir do interesse do sujeito que comanda a interação, o enunciador" (OLIVEIRA, 2013, p. 245).

A enunciação em uma obra dessa natureza define onde estará o ponto de captação, que pode ser o mesmo durante todo o vídeo, mover-se pela cena, ou, em alguns casos, saltar de um a outro lugar com o recurso do corte. Apesar de captar tudo ao redor, a imagem resultante desses processos continua sendo, em qualquer um desses casos, uma representação perspectivista. A diferença com o audiovisual baseado na montagem "tradicional" é que, nestes casos, o observador tem o poder de escolher tanto a orientação quanto a sequência visual a ser acompanhada. Enquanto enunciatário pressuposto no texto, ele decide quais serão suas escolhas durante a navegação. Além disso, por escolher a ordem visual, ele mesmo constrói, à medida que o enunciado prevê, o acesso à significação, dividindo com o enunciador o papel de narrador. Nota-se um sincretismo de papéis actanciais. Para que ocorra a manifestação, o mesmo sujeito assume os papéis de destinatário, enunciatário e narrador do vídeo panorâmico, e isso só é possível graças ao movimento desempenhado por ele.

É possível afirmar, portanto, que a possibilidade de navegação visual do vídeo panorâmico configura uma espécie de montagem espacializada, como a nomeia Dubois (2014) ao refletir sobre as produções audiovisuais multitela. Segundo o autor, "a narratividade espacial implica pensar a ação física do espectador (seu percurso) como performance" (DUBOIS, 2014, p. 147). Esse raciocínio é aplicável ao vídeo panorâmico, uma vez que, assim como em uma instalação, é possível dar ao destinatário do vídeo $360^{\circ}$ o poder de mudar a sua orientação em um espaço com possibilidades visuais, criando a sua ordem de elementos à medida que decide onde focar a sua atenção. A diferença está, no entanto, em explorar o ambiente ficcional criado, que simula um outro espaço. Este 
aspecto fica evidente em Duet, já que o enunciatário deve obrigatoriamente escolher por meio da orientação visual o sujeito que irá acompanhar.

Cabe, aqui, uma reflexão sobre um aspecto fundamental da enunciação no audiovisual panorâmico. Há dois espaços em relação: o espaço do enunciado, instaurado na dimensão enunciativa exibida na tela do dispositivo, e o espaço da enunciação, instância na qual o enunciatário implícito é atualizado. Esses dois espaços coincidem durante a navegação. O enunciado é construído tendo em vista a navegação espacial que o enunciatário fará no dispositivo, e esse fator pauta as outras categorias enunciativas, de pessoa e de tempo. Observa-se, portanto, uma centralidade na categoria espacial no processo de discursivização.

A navegação espacial associada ao movimento desempenhado no dispositivo não é observada apenas nos elementos visuais. $\mathrm{O}$ som também pode ser panorâmico. No recurso chamado de Soundsphere, apresentado em Help, a mesma configuração entre o movimento do corpo e a sensibilidade espacial ocorre também por meio do som. A técnica consiste em situar as fontes sonoras representadas no enunciado de acordo com a disposição delas durante a navegação visual: dessa forma, se o ponto de captação estiver fixo e o enunciatário girar o corpo, o efeito no fone de ouvido associado ao recurso de áudio binaural ${ }^{6}$ - é de que a fonte sonora de determinado elemento permaneceu no mesmo lugar. Por situar num ambiente tridimensional as fontes sonoras do enunciado, o recurso dá ao destinatário a capacidade de conseguir sentir, interpretar e deduzir com a audição de qual orientação provém a fonte sonora, o que intensifica não apenas com a imersão, mas permite que ele escolha qual fonte pretende enquadrar. Essa sensibilidade só é notada durante o movimento - pois se o aparelho estiver estático o som será percebido como um estéreo regular. Como apontou Chion (2011), a imagem continua sendo a referência para quais sons estão inscritos, mas a movimentação do corpo através do espaço no Soundsphere e na perspectiva sonora programada permite, mesmo com o estéreo, uma espacialização sonora da cena. A movimentação do dispositivo torna possível uma dimensão sonora também espacial - e não só temporal, como apontou Chion (2011) ao tratar do cinema clássico.

É importante observar que essa relação entre os dois atores da enunciação acontece por meio dos dispositivos eletrônicos, e são suas especificidades que tornam o espaço sensível. De acordo com Landowski (2014), os objetos inanimados podem ser capazes de simular uma sensibilidade do tipo reativa, suscetível de fundar os processos de

\footnotetext{
${ }^{6}$ Modalidade de gravação que utiliza dois microfones posicionados na mesma disposição dos ouvidos humanos. Quando este áudio é ouvido separadamente com fones de ouvido (microfone esquerdo sendo ouvido pelo ouvido esquerdo e microfone direito pelo ouvido direito), o resultado é a sensação de que se está presente no local do áudio captado (ARRUDA, 2011).
} 
ajustamento - interação que acontece por meio de um fazer junto, uma união. Segundo o autor, essa capacidade de sentir reciprocamente é chamada de competência estésica.

As especificidades dos meios digitais, como a mobilidade, e suas tecnologias associadas, como a tela sensível ao toque e os sensores de movimento, dão aos dispositivos digitais a possibilidade de simular uma "competência estésica" que os tornam capazes de produzir um efeito de sentido de ajustamento entre um ser humano e o conteúdo manifestado por um objeto inanimado. A maneira como o enunciador dispõe o conteúdo no vídeo panorâmico simula as condições espaciais do mundo natural, e os processos de significação acontecem graças a essa configuração. Em outras palavras, o enunciador fundamenta o processo comunicativo na partilha da sensibilidade espacial com o enunciatário através do dispositivo digital e a capacidade deste de "sentir" o espaço e de poder ser reposicionado nele.

Essa sensorialidade espacial é um dos fatores que constroem a imersão no vídeo panorâmico. Ela assume, nesse caso, uma função diferenciada: enquanto no audiovisual clássico ela é buscada para servir à transparência enunciativa, no panorâmico ela serve à participação, e esta, por sua vez, ocasiona a transparência do meio.

\section{Considerações finais}

Este artigo procurou demonstrar como as novas lógicas de linearidade estabelecidas no audiovisual, quando utilizado o recurso do vídeo $360^{\circ}$, reconfiguram as práticas de fruição desta linguagem. Da mesma forma que o corte, os movimentos de câmera e lentes, os ângulos e enquadramentos são exemplos de recursos utilizados na montagem clássica, é importante levar em conta, na montagem do vídeo panorâmico, novos elementos que também são responsáveis pela produção do sentido do filme. Parte do enunciador as estratégias de discursivização no vídeo panorâmico, mas é preciso considerar que a base estrutural da textualização compreende intrinsecamente várias possibilidades de escolhas do enunciatário diante dos arranjos enunciativos. Apesar da representação imagética permanecer perspectivista e a ordenação de enquadramentos e movimentos na imagem continuar presente, a construção desse conteúdo, que no audiovisual clássico é controlada até a composição final, opera, no vídeo panorâmico, como um conjunto de possibilidades oferecidas a partir de um ambiente visual navegável. Pode-se afirmar, portanto, que os arranjos enunciativos relativos ao enunciador atuam na categoria englobante e sugerem percursos de leitura, enquanto ao enunciatário cabe a montagem, a partir do recorte da tela, da sua própria sequência, sendo essas possibilidades sequências englobadas. 
Verifica-se no vídeo panorâmico o sincretismo de papéis actanciais, uma vez que o enunciatário compartilha muitas vezes a função de narrador no enunciado. Se a narração é atualizada justamente nesta debreagem enunciativa, que no plano englobante atribui a competência semântica e modal para um fazerfazer do enunciatário, esse sincretismo realizado a partir do movimento corpóreo em conjunção com o dispositivo rege as projeções do espaço, que por sua vez estão articuladas com as estratégias enunciativas de produção do sentido. A ênfase desta análise na discursivização da categoria espacial demonstrou que as projeções espaciais convocam uma dimensão sensível, em um movimento corpóreo que ancora o processo de fruição, de imersão e de significação.

\section{Referências}

ARRUDA, F. Áudio binaural: efeito 3D em fones de ouvido estéreo. Tecmundo, Curitiba, 18 jul. 2011. Disponível em: <https://goo.gl/Gk9Y4C>. Acesso em 19 out. 2017.

BERTRAND, D. Caminhos da semiótica literária. Bauru: Edusc, 2003.

CHION, M. A audiovisão: som e imagem no cinema. Lisboa: Texto \& Grafia, 2011.

DUBOIS, P. “A questão da 'forma-tela': espaço, luz, narração, espectador”. In: GONÇALVES, O. (Org.). Narrativas sensoriais: ensaios sobre cinema e arte contemporânea. Rio de Janeiro: Circuito, 2014. p. 123-157.

ECO, U. Obra aberta. 8. ed. São Paulo: Perspectiva, 1991.

EISENSTEIN, S. A forma do filme. Rio de Janeiro: Jorge Zahar, 2008.

FIORIN, J. L. “Teoria dos signos". In: . (Org.). Introdução à lingüística: objetos teóricos. 4 ed. São Paulo: Contexto, 2005. v. 1, p. 55-74.

Paulo: Astica, 1996.

As astúcias da enunciação: as categorias de pessoa, espaço e tempo. São

FLOCH, J-M. Petites mythologies de l'oeil et de l'esprit: pour une sémiotique plastique. Paris; Amsterdam: Hadès-Benjamins, 1985.

GREIMAS, A. J.; COURTÉS, J. Dicionário de semiótica. Tradução Alceu Dias Lima et al. São Paulo: Contexto, 2008.

HJELMSLEV, L. Prolegômenos a uma teoria da linguagem. Tradução José Teixeira Coelho Netto. São Paulo: Perspectiva, 1975.

LANDOWSKI, E. Interações arriscadas. Tradução Luiza Helena Oliveira da Silva. São Paulo: Estação das Letras e Cores, 2014.

MACHADO, A. A ilusão especular: uma teoria da fotografia. São Paulo: Brasiliense, 1984. 
Pré-cinemas e pós-cinemas. Campinas: Papirus, 1997.

O sujeito na tela: modos de enunciação no cinema e no ciberespaço. São Paulo: Paulus, 2007.

MANOVICH, L. The language of new media. Cambridge, MA: The MIT Press, 2001.

MURRAY, J. H. Hamlet no holodeck: o futuro da narrativa no ciberespaço. Tradução Elissa Khoury Daher e Marcelo Cuzziol. São Paulo: Unesp; Itaú Cultural, 2003.

OLIVEIRA, A. C. "As interações discursivas". In: OLIVEIRA, A. C. (Ed.). As interações sensiveis: ensaios de sociossemiótica a partir da obra de Eric Landowski. São Paulo: Estação das Letras e das Cores, 2013. p. 235-251.

TARKOVSKI, A. Esculpir o tempo. 2. ed. São Paulo: Martins Fontes, 1998.

submetido em: 14 ago. 2017 | aprovado em: 30 set. 2017 